\title{
Incidence and predictors of unplanned non-target lesion revascularisation up to three years after drug-eluting stent implantation: insights from a pooled analysis of the RESOLUTE Global Clinical Trial Program
}

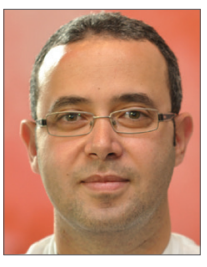

Mohamed Abdel-Wahab ${ }^{1 *}$, MD; Franz-Joseph Neumann², MD; Patrick Serruys ${ }^{3}$, MD, PhD; Sigmund Silber ${ }^{4}, \mathrm{MD}, \mathrm{PhD}$; Martin Leon ${ }^{5}$ MD; Laura Mauri ${ }^{6}, \mathrm{MD}, \mathrm{MSc}$; Alan Yeung ${ }^{7}, \mathrm{MD}$; Jorge A. Belardi ${ }^{8}, \mathrm{MD}$; Petr Widimský ${ }^{9}, \mathrm{MD}$, DrSc; Ian Meredith ${ }^{10}, \mathrm{MBBS}, \mathrm{PhD}$; Shigeru Saito ${ }^{11}$, MD; Gert Richardt ${ }^{1}, \mathrm{MD}$

1. Heart Center, Segeberger Kliniken, Bad Segeberg, Germany; 2. Heart Center Bad Krozingen, Bad Krozingen, Germany; 3. Thoraxcenter-Erasmus University, Rotterdam, The Netherlands; 4. Heart Center at the Isar, Munich, Germany; 5. Columbia University Medical Center and New York-Presbyterian Hospital, New York, NY, USA; 6. Brigham and Women's Hospital and Harvard Medical School, Boston, MA, USA; 7. Stanford University School of Medicine, Stanford, CA, USA; 8. Instituto Cardiovascular de Buenos Aires, Buenos Aires, Argentina; 9. Third Faculty of Medicine, Charles University, Prague, Czech Republic; 10. Monash University, Melbourne, Australia; 11. Shonan Kamakura General Hospital, Kanagawa, Japan

GUEST EDITOR: Rafael Beyar, MD, DSc, MPH; Director, Rambam Health Care Campus, Women's Division/Dr Phillip and Sara Gotlieb Chair, Department of Medicine and Biomedical Engineering, Technion, Israel

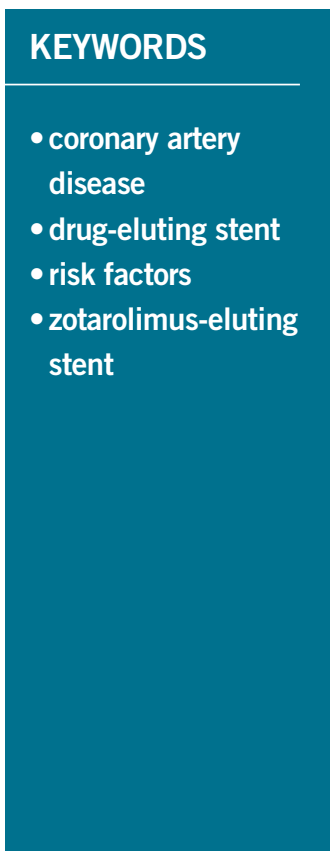

\begin{abstract}
Aims: To compare the incidence and predictors of target lesion revascularisation (TLR) and non-TLR after percutaneous coronary intervention with drug-eluting stents (DES).

Methods and results: We pooled patient-level data on 6,137 patients (Resolute zotarolimus-eluting stent: 5,016, XIENCE everolimus-eluting stent: 1,121) in the RESOLUTE Global Program. At three years, clinically driven TLR, unplanned non-TLR, and no revascularisation occurred in 186, 618, and 5,333 patients, respectively. On multivariate analysis, predictors of both TLR and non-TLR were pre-procedure diameter stenosis (\%) (odds ratio [OR] 1.01, 95\% confidence interval [CI] [1.01-1.02], and OR 0.99 [0.99-1.00]), diabetes (OR 1.46 [1.07-1.99], and OR 1.37 [1.15-1.64]), and prior PCI (OR 1.42 [1.01-2.00], and OR 1.41 [1.181.68]). Baseline characteristics associated with TLR only were prior coronary artery bypass graft surgery (OR 2.85 [1.91-4.27]), in-stent restenosis (OR 2.35 [1.43-3.83]), age (OR 0.98 per year [0.97-1.00]), hypertension (OR 1.64 [1.10-2.44]), and pre-procedure reference vessel diameter (OR 0.74 per mm [0.55-0.99]). Baseline characteristics associated with non-TLR only were lesion location (left anterior descending vs. all others) (OR 0.70 [0.59-0.83]), and hyperlipidaemia (OR 1.42 [1.15-1.75]).
\end{abstract}

Conclusions: The cumulative incidence of non-TLR at three years in patients treated with current-generation DES was almost three times higher than TLR.

\footnotetext{
* Corresponding author: Herzzentrum, Segeberger Kliniken GmbH, Am Kurpark 1, 23795 Bad Segeberg, Germany. E-mail: mohamed.abdel-wahab@segebergerkliniken.de
} 


\section{Introduction}

First-generation drug-eluting stents (DES) substantially decreased angiographic and clinical restenosis after percutaneous coronary intervention (PCI ${ }^{1,2}$. Newer DES, such as Resolute ${ }^{\mathrm{TM}}$ zotarolimuseluting stents (R-ZES; Medtronic, Minneapolis, MN, USA) and XIENCE $\mathrm{V}^{\circledR}$ everolimus-eluting stents (EES) (Abbott Vascular, Santa Clara, CA, USA), further improved the long-term safety and efficacy of DES with reductions of stent thrombosis and target lesion reintervention compared to first-generation $\mathrm{DES}^{3-6}$. The highly effective DES-based local therapy of coronary lesions is currently applied in a wide spectrum of patients, including those with advanced coronary artery disease and complex anatomy $y^{5,7,8}$. Consequently, cardiac events that are not stent-related are prominent in the follow-up of contemporary PCI populations. Therefore, anticipation and prevention of disease progression in non-intervened non-target lesions is gaining increasing attention.

To assess the incidence and risk factors associated with clinical plaque progression requiring non-target lesion revascularisation during long-term follow-up after culprit lesion PCI with modern DES, patient-level data were pooled from five clinical trials of the RESOLUTE Global Clinical Trial Program with harmonised endpoint definitions (RESOLUTE First-in-Man, RESOLUTE All Comers, RESOLUTE International, RESOLUTE US and RESOLUTE Japan) $)^{3,8-16}$

\section{Methods}

Our retrospective analysis pooled data from all patients in the RESOLUTE First-in-Man (FIM) (R-ZES: $n=139)^{11,12}$, RESOLUTE All Comers (R-ZES: $n=1,140$, EES: $n=1,152)^{3,8,15}$, RESOLUTE International (R-ZES: $\mathrm{n}=2,349)^{9,13}$, RESOLUTE US (R-ZES: $\mathrm{n}=1,402)^{10,16}$, and RESOLUTE Japan (R-ZES: $\left.\mathrm{n}=100\right)^{14}$ trials. The methods for these studies have been previously described. Briefly, RESOLUTE FIM ${ }^{11,12}$ was a first-in-man R-ZES study in Australia and New Zealand, RESOLUTE All Comers ${ }^{3,8,15}$ was a randomised comparison of R-ZES to EES in a real-world all-comers population in Europe, RESOLUTE International ${ }^{9,13}$ was a worldwide registry using R-ZES in a real-world all-comers population, and RESOLUTE US $^{10,16}$ and RESOLUTE Japan ${ }^{14}$ were "on-label" studies using R-ZES in the United States of America and Japan, respectively. All patients provided written informed consent and the protocols were approved by institutional review boards or ethics committees at all sites.

Inclusion and exclusion criteria varied within each study and have been reported previously. RESOLUTE FIM enrolled single-lesion patients with a simple disease state, RESOLUTE US and RESOLUTE Japan enrolled "on-label" single- and dualvessel patients, and RESOLUTE All Comers and RESOLUTE International enrolled patients without restrictions on the number of lesions or vessels treated. Dual antiplatelet therapy before implantation included daily aspirin $75 \mathrm{mg}$ and clopidogrel either daily $75 \mathrm{mg}$ or a $\geq 300 \mathrm{mg}$ loading dose. After the procedure, patients were required to continue daily aspirin $75 \mathrm{mg}$ indefinitely and daily clopidogrel $75 \mathrm{mg}$, for a minimum of six months in all patients and up to 12 months in patients who were not at high risk of bleeding.
Baseline lesion characteristics were determined by an independent core laboratory in all studies except RESOLUTE International (site-reported visual estimation). Follow-up was done in-clinic or by telephone.

For this analysis, patients were grouped as follows based on their outcomes up to three years of follow-up: target lesion revascularisation (TLR), non-TLR, and no revascularisation. Patients requiring both TLR and non-TLR were excluded from the analysis. Revascularisations could be percutaneous or surgical. A non-TLR was defined as an unplanned procedure elsewhere in the target vessel or in other coronary arteries.

The studies contributing to this analysis used harmonised, validated endpoint definitions. Study-specific clinical event committees composed of interventional cardiologists not directly involved in the study applied these definitions to all suspected events.

Data safety monitoring boards were composed of non-interventional and interventional cardiologists not directly involved in the study. Each study's data safety monitoring board reviewed adverse event data and could recommend stopping the study. Clinical event committees and data safety monitoring boards were coordinated by independent academic research organisations.

\section{Statistical analysis}

All analyses were conducted on an intention-to-treat basis. Continuous parameters were presented as mean \pm standard deviation and compared using a t-test or Wilcoxon rank-sum test, as appropriate. Nominal parameters were presented as percentages and compared using Fisher's exact test. Time to event endpoints were calculated using the Kaplan-Meier method and compared using the log-rank test. Multivariate stepwise regression analysis was conducted to assess independent correlates of TLR and non-TLR at three years of follow-up. A simple logistic regression was performed using the following baseline characteristics: prior coronary artery bypass graft, in-stent restenosis, prior PCI, history of diabetes, hypertension, hyperlipidaemia, pre-procedure diameter stenosis (\%), previous myocardial infarction (MI), lesion length (mm), pre-procedure reference vessel diameter (RVD) $(\mathrm{mm})$, bend $\geq 45^{\circ}$, calcification (moderate/severe vs. none/mild), TIMI flow 3 , age (years), male sex, serum creatinine $(\mu \mathrm{mol} / \mathrm{L})$, vessel location (left anterior descending vs. other), lesion class B2/C, unstable angina, and current smoker. Then, a multiple logistic regression was performed with an entry criterion of 0.20 and a stay criterion of 0.10 . Analyses were performed using SAS software version 9.1 or later (SAS Institute, Cary, NC, USA). A p-value $<0.05$ was considered statistically significant.

\section{Results PATIENT/SUBJECT DISPOSITION AND CHARACTERISTICS}

The five RESOLUTE studies contributing to this analysis enrolled 6,282 patients (R-ZES: 5,130, EES: 1,152). At three years, the incidence of clinically driven TLR was $5.3 \%$ and unplanned nonTLR was $12.1 \%$. After excluding 145 patients who had both clinically driven TLR and unplanned non-TLR, 6,137 patients (R-ZES: 
5,016, EES: 1,121) were included in the analysis, of whom $186 \mathrm{had}$ clinically driven TLR, 618 had unplanned non-TLR, and 5,333 had no revascularisation at three years. Among the 618 patients with non-TLR, 162 patients (26\%) had non-TL TVR and 518 patients (84\%) had revascularisation outside the target vessel.

\section{TIMING AND PREDICTORS OF REPEAT REVASCULARISATION}

TLR was numerically more frequent than non-TLR only within the first 20 days after the index procedure (Figure 1A). Thereafter, the Kaplan-Meier curves crossed, and TLR and non-TLR rates further divided over time. The separation was most prominent in the second and third years of follow-up (Figure 1B).

Compared to patients with no revascularisation, those with TLR and with non-TLR were more likely to have diabetes, insulin-dependent diabetes, and a history of cardiovascular procedures and disorders (Table 1). Patients with TLR were also more likely to have Canadian Cardiovascular Society class III angina. Patients with non-TLR had a higher mean BMI, greater number of native vessels with $>50 \%$ diameter stenosis, and a greater incidence of stable angina and lesser incidence of MI as the reason for revascularisation (Table 1).

Prior in-stent restenosis was significantly more common in TLR patients than in patients with no revascularisation (Table 2). Compared to patients with no revascularisation, those with nonTLR had fewer lesions in the left anterior descending and left main coronary arteries, and fewer lesions with thrombus (Table 2).

A multivariate analysis was conducted to determine predictors of TLR (Figure 2A) and non-TLR (Figure 2B) at three years.

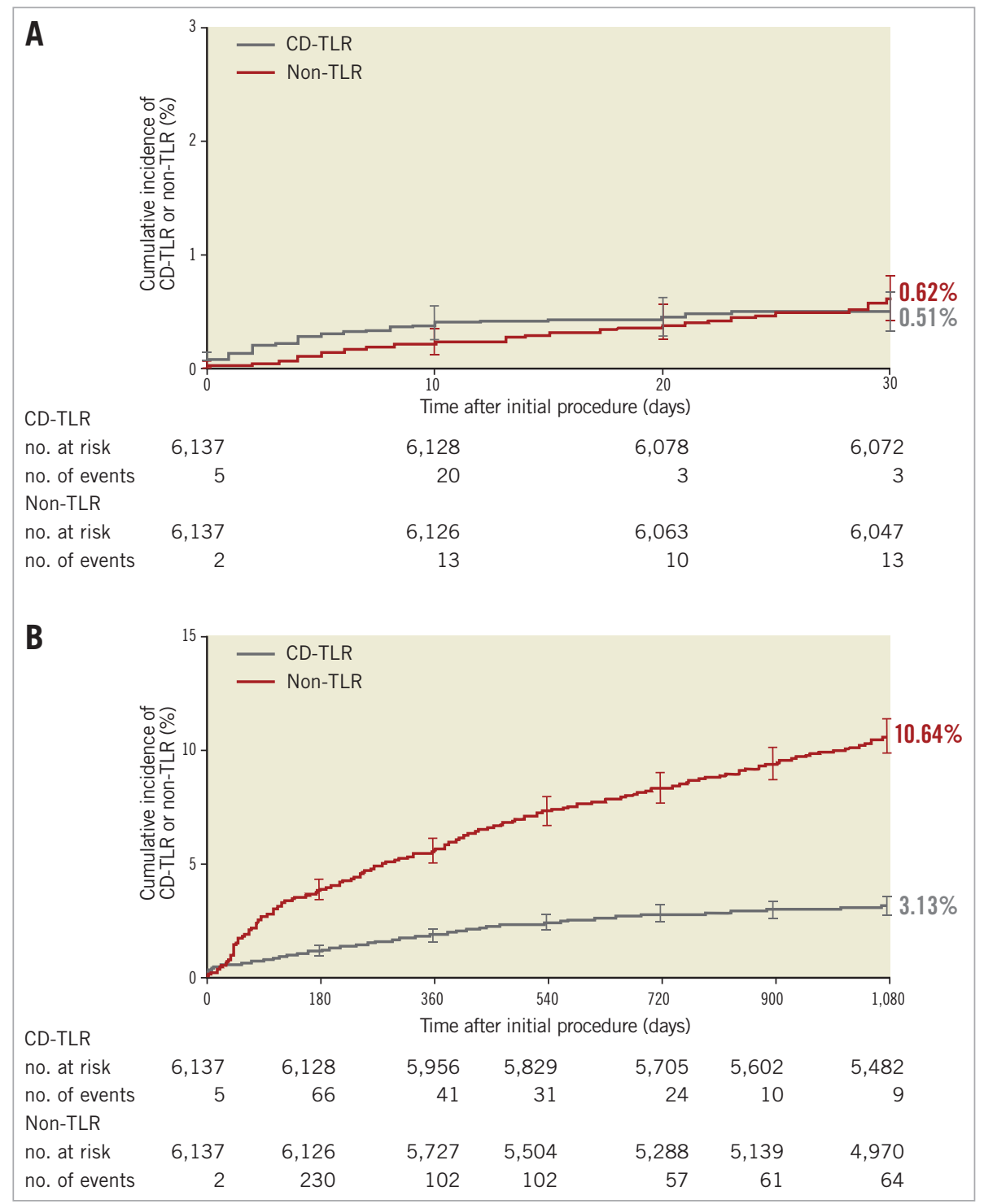

Figure 1. Cumulative incidence of clinically driven target lesion revascularisation and unplanned non-target lesion revascularisation. A) Up to 30 days $(p=0.394)$ and $B)$ up to three years $(p<0.001)$. The cumulative incidence of clinical events was calculated using the Kaplan-Meier method and compared using the log-rank test. CD-TLR: clinically driven target lesion revascularisation. 
Table 1. Baseline characteristics of patients with clinically driven target lesion revascularisation (TLR), unplanned non-target lesion revascularisation (Non-TLR), and no revascularisation at three years of follow-up.

\begin{tabular}{|c|c|c|c|c|c|c|}
\hline \multicolumn{2}{|l|}{ 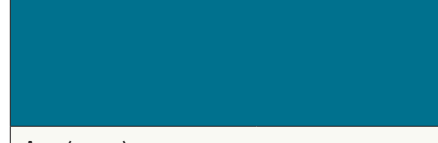 } & $\begin{array}{c}\text { TLR } \\
(\mathrm{N}=186)\end{array}$ & $\begin{array}{c}\text { TLR vs. } \\
\text { no revascularisation } \\
p \text {-value }\end{array}$ & $\begin{array}{l}\text { Non-TIR } \\
(N=618)\end{array}$ & $\begin{array}{c}\text { Non-TLR vs. } \\
\text { no revascularisation } \\
p \text {-value }\end{array}$ & $\begin{array}{l}\text { No revascularisation } \\
\qquad(\mathbb{N}=5,333)\end{array}$ \\
\hline \multicolumn{2}{|l|}{ Age (years) } & $63.2 \pm 11.8(186)$ & 0.348 & $64.4 \pm 10.8(618)$ & 0.260 & $63.9 \pm 10.9(5,333)$ \\
\hline \multicolumn{2}{|l|}{ Male } & $78.0 \%(145 / 186)$ & 0.437 & $75.1 \%(464 / 618)$ & 0.922 & $75.3 \%(4,015 / 5,333)$ \\
\hline \multicolumn{2}{|c|}{ Body mass index, $\mathrm{kg} / \mathrm{m}^{2}$} & $28.3 \pm 4.8(186)$ & 0.997 & $28.9 \pm 5.3(618)$ & 0.008 & $28.3 \pm 5.0(5,323)$ \\
\hline \multicolumn{2}{|l|}{ Prior Ml } & $33.3 \%(61 / 183)$ & 0.033 & $31.0 \%(190 / 612)$ & 0.012 & $26.2 \%(1,380 / 5,268)$ \\
\hline \multicolumn{2}{|l|}{ Prior $\mathrm{PCl}$} & $43.0 \%(80 / 186)$ & $<0.001$ & $40.0 \%(247 / 618)$ & $<0.001$ & $29.1 \%(1,554 / 5,333)$ \\
\hline \multicolumn{2}{|c|}{ Ejection fraction (\%) } & $59.0 \pm 10.7(65)$ & 0.171 & $56.5 \pm 10.9(285)$ & 0.294 & $57.2 \pm 10.7(2,173)$ \\
\hline \multicolumn{2}{|l|}{ Prior CABG } & $18.8 \%(35 / 186)$ & $<0.001$ & $11.8 \%(73 / 618)$ & 0.001 & $7.8 \%(415 / 5,333)$ \\
\hline \multicolumn{2}{|l|}{ Diabetes mellitus } & $37.6 \%(70 / 186)$ & 0.003 & $35.8 \%(221 / 618)$ & $<0.001$ & $27.3 \%(1,458 / 5,333)$ \\
\hline \multicolumn{2}{|l|}{ Insulin-dependent } & $12.4 \%(23 / 186)$ & 0.027 & $11.2 \%(69 / 618)$ & 0.005 & $7.8 \%(414 / 5,333)$ \\
\hline \multicolumn{2}{|c|}{ History of hypertension } & $82.3 \%(153 / 186)$ & 0.002 & $76.9 \%(475 / 618)$ & 0.013 & $72.1 \%(3,846 / 5,333)$ \\
\hline \multicolumn{2}{|c|}{ History of hyperlipidaemia } & $78.5 \%(146 / 186)$ & 0.007 & $79.1 \%(489 / 618)$ & $<0.001$ & $69.3 \%(3,698 / 5,333)$ \\
\hline \multicolumn{2}{|l|}{ Current smoker } & $24.2 \%(45 / 186)$ & $>0.99$ & $22.8 \%(141 / 618)$ & 0.486 & $24.1 \%(1,286 / 5,333)$ \\
\hline \multicolumn{2}{|c|}{ Multivessel disease (>50\% stenosis) } & $54.6 \%(59 / 108)$ & 0.142 & $63.9 \%(276 / 432)$ & $<0.001$ & $47.1 \%(1,553 / 3,300)$ \\
\hline \multirow{3}{*}{$\begin{array}{l}\text { Reason for } \\
\text { revascularisation }\end{array}$} & Stable angina & $44.1 \%(82 / 186)$ & 0.076 & $41.7 \%(258 / 618)$ & 0.040 & $37.4 \%(1,997 / 5,333)$ \\
\hline & Unstable angina & $26.9 \%(50 / 186)$ & 0.435 & $25.6 \%(158 / 618)$ & 0.521 & $24.4 \%(1,300 / 5,333)$ \\
\hline & MI & $23.1 \%(43 / 186)$ & 0.606 & $20.6 \%(127 / 618)$ & 0.014 & $25.1 \%(1,339 / 5,333)$ \\
\hline
\end{tabular}

Results presented as either mean \pm SD $(\mathrm{n} / \mathrm{N})$ or percent $(\mathrm{n} / \mathrm{N})$. CABG: coronary artery bypass graft surgery; MI: myocardial infarction; PCl: percutaneous coronary intervention

Predictors of both TLR and non-TLR were pre-procedure diameter stenosis (\%), history of diabetes, and prior PCI. Notably, the degree of pre-procedural diameter stenosis $(\%)$ was positively correlated with TLR and negatively correlated with non-TLR. Predictors of
TLR only were prior CABG, in-stent restenosis, age (years) (lower age was associated with higher risk for TLR), history of hypertension, and pre-procedure RVD (mm) (lower pre-procedure RVD was associated with higher risk for TLR). Predictors of non-TLR

Table 2. Lesion characteristics of patients with clinically driven target lesion revascularisation (TLR), unplanned non-target lesion revascularisation (Non-TLR), and no revascularisation at three years of follow-up.

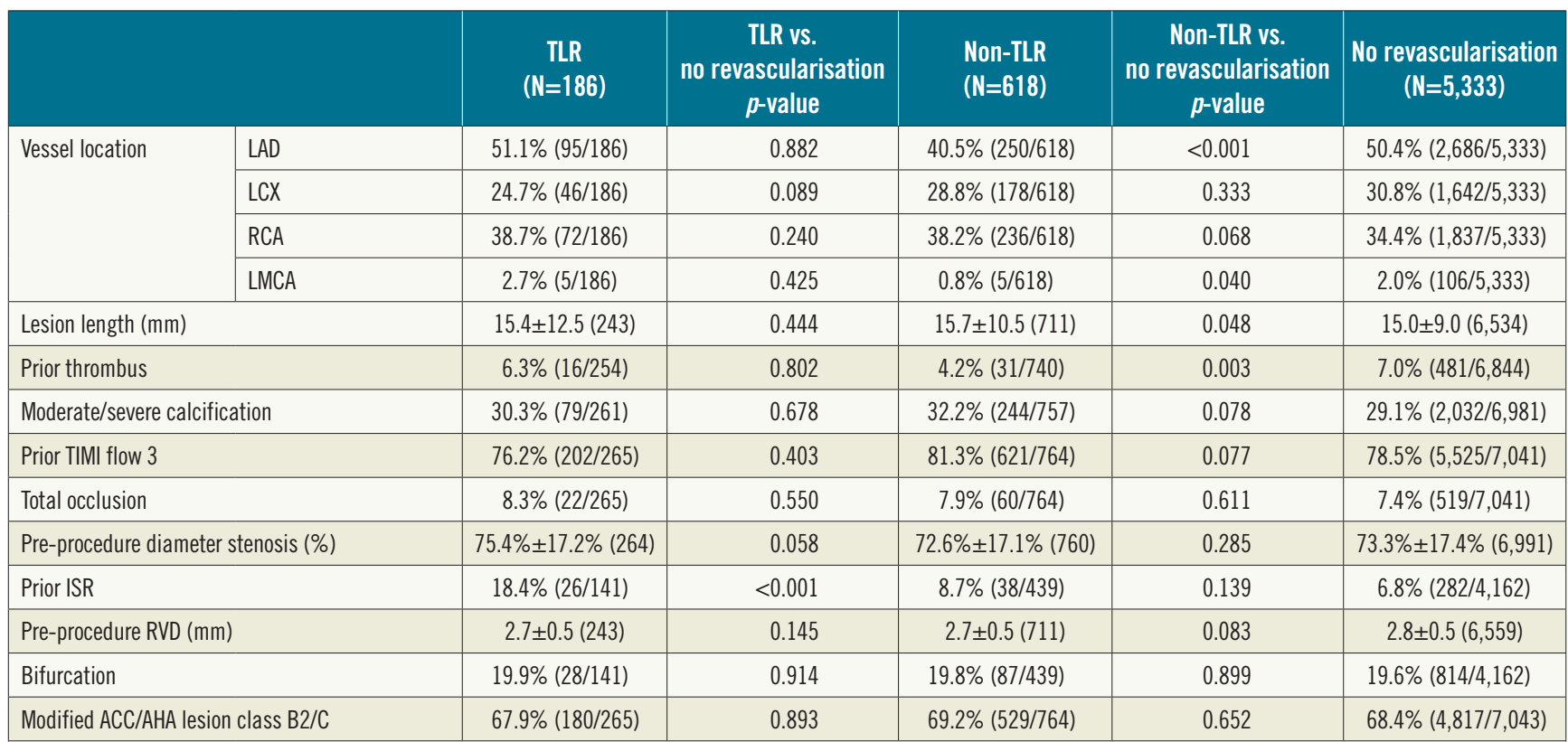

Results presented as either mean $\pm S D(n / N)$ or percent (n/N). ISR: in-stent restenosis; LAD: left anterior descending; LCX: left circumflex artery; LMCA: left main coronary artery; RCA: right coronary artery; RVD: reference vessel diameter; TIMI: Thrombolysis In Myocardial Infarction 


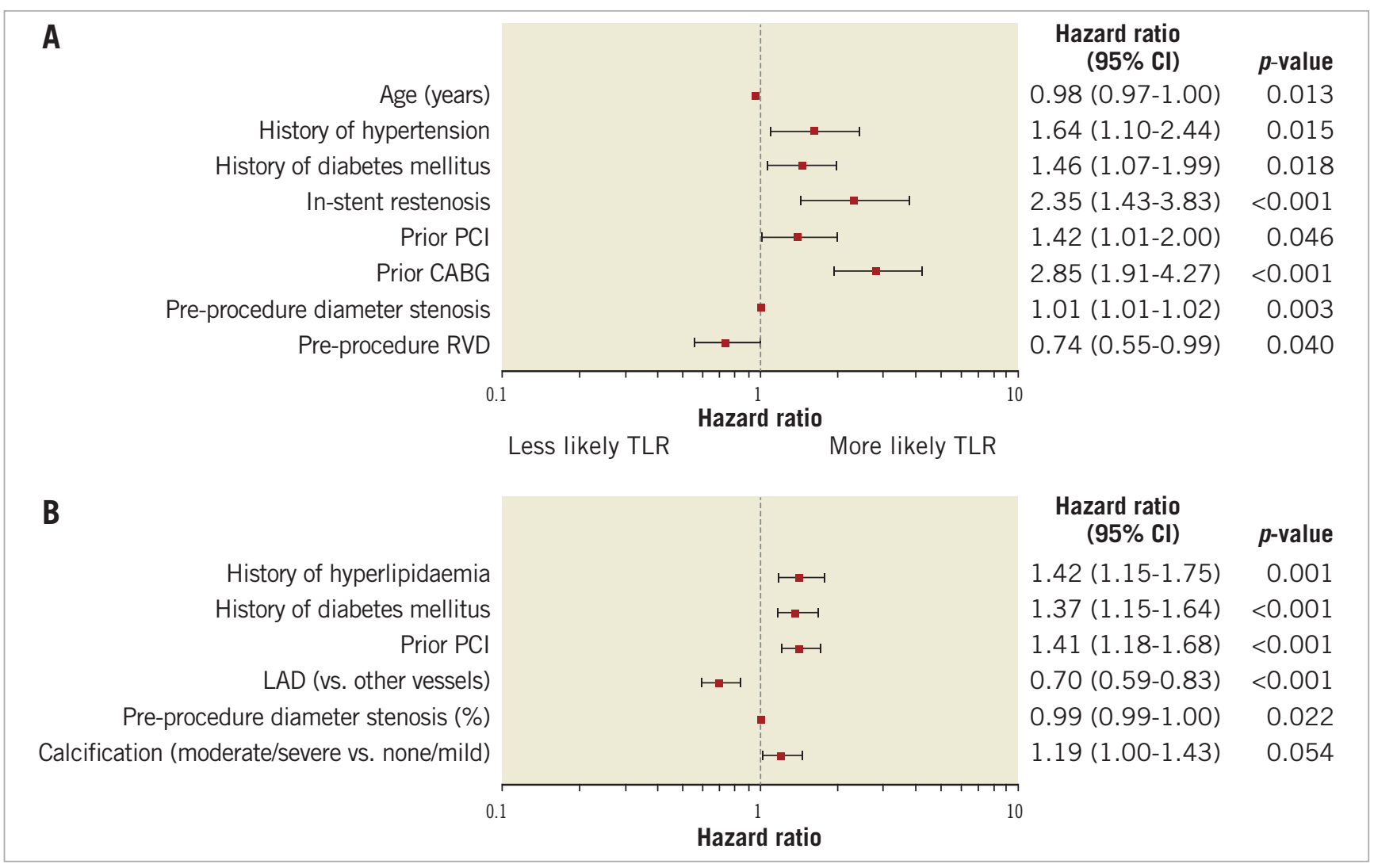

Figure 2. Forest plot predictors at three years. A) Clinically driven target lesion revascularisation and B) unplanned non-target lesion revascularisation. Analysis conducted using multivariate stepwise regression. CABG: coronary artery bypass graft surgery; LAD: left anterior descending artery; PCI: percutaneous coronary intervention; RVD: reference vessel diameter

only were lesion location (non-left anterior descending [LAD]) (LAD was associated with a lower risk of non-TLR), and history of hyperlipidaemia.

\section{Discussion}

The principal finding of our study was that non-TLR occurred more frequently than TLR throughout the three-year observation period of our patient cohort, which comprised more than 6,100 predominantly "all-comer" PCI patients treated with current-generation DES. Nearly $11 \%$ of the patients had clinical plaque progression requiring non-TLR at three years, which was approximately three times higher than the observed TLR rate. However, non-TLR, particularly those events that occurred shortly after the index procedure, could be overestimated as some cases might have been due to incomplete coverage during revascularisation of a diffuse lesion.

Non-TLR was infrequently described in the balloon angioplasty and bare metal stent eras, because restenosis rates were high, observation periods were short, and less complex patients were included in PCI studies. Our investigation with modern DES unmasks the true burden of unplanned revascularisations in the PCI landscape.

Other studies have also examined the incidence of TLR vs. nonTLR after PCI. PROSPECT (Providing Regional Observations to Study Predictors of Events in the Coronary Tree $)^{17}$ evaluated originally treated (culprit) and untreated (non-culprit) lesionrelated adverse events among 697 patients with acute coronary syndromes who successfully underwent PCI during a follow-up of 3.4 years $^{17}$. The study reported revascularisation rates in the treated $(10.9 \%)$ vs. non-treated $(10.5 \%)$ lesions at three years of followup $^{17}$. Additionally, the EVENT (Evaluation of Drug-Eluting Stents and Ischemic Events) registry included 10,144 patients, of whom 1,207 underwent repeat PCI, and found a similar rate of unplanned TLR vs. unplanned non-TLR at one year $(4.5 \%$ vs. $4.4 \%$, respectively) ${ }^{18}$. In an analysis in SIRIUS (Sirolimus-Eluting Stent in De Novo Native Coronary Lesions) with sirolimus-eluting stents (SES) at five years, TLR was $12.5 \%$, TVR-non TL was $11.7 \%$, and non-target vessel revascularisation was $22.3 \%$. Thus, the ratio of TLR to non-TLR (TVR-non TL and non-target vessel revascularisation) was roughly $1: 3$ at five years ${ }^{19}$.

\section{TIME COURSE OF REVASCULARISATION}

The current analysis was unique from PROSPECT and EVENT in that the Kaplan-Meier curves of TLR and non-TLR in our analysis separated early after the index procedure and non-TLR became more frequent than TLR as early as 30 days after the procedure. Such an early dissociation of curves is unexpected, as one would expect that they would separate later. The curves further divided 
over time, with a slower proportional increase of TLR than nonTLR after one year. Obviously, plaque progression in non-target lesions occurred in a continuous manner, while pathological processes in the target lesions cooled down over time. The risk of TLR was highest in the first year. Afterwards, the event rate for TLR was very low (roughly $0.7 \%$ per year). The fact that TLR is most common in the first year after PCI is seen across DES studies ${ }^{20-22}$. In EVENT, the risk of non-TLR was constant over time, while the hazard ratio for TLR was highest between two to nine months after $\mathrm{PCI}^{18}$. This trend in the first year could be due to trauma to the vessel during stent delivery.

\section{PREDICTORS OF REVASCULARISATION}

For TLR, features of lesion morphology - such as the presence of restenotic lesions, a smaller reference vessel diameter and larger preprocedure diameter stenosis - were identified as independent predictors of repeat TLR. Moreover, previous revascularisations with either prior PCI or CABG were independent predictors of TLR. With respect to clinical characteristics, hypertension and diabetes mellitus, in addition to age, continue to represent significant predictors of TLR. Predictors of non-TLR included lesion characteristics (smaller pre-procedure diameter stenosis, and non-LAD lesion location), and clinical characteristics (history of diabetes, hyperlipidaemia, and prior PCI). Diabetes mellitus (along with prior PCI and pre-procedure diameter stenosis) was a predictor of both TLR and non-TLR. Given the prevalence of diabetes mellitus and its clinical significance, analysis on subjects with diabetes mellitus was a pre-specified secondary objective in the RESOLUTE Global Clinical Program ${ }^{23}$.

Other studies are available on predictors of TLR and non-TLR among patients treated with coronary stent implantation. Similar to this analysis, the EVENT registry found predictors of TLR to include age, prior PCI, and minimum stent diameter (which is similar to our finding of pre-procedure RVD) ${ }^{18}$. EVENT also found predictors of TLR to include sex, smoking status, prior MI, PCI of the left main or saphenous vein graft, total stent length, and use of a bare metal stent ( $18 \%$ of patients did not receive a DES but only BMS $)^{18}$. Predictors of non-TLR in EVENT were different from this study and included age, number of diseased coronary arteries, and vein graft $\mathrm{PCI}^{18}$. Similar to our study, in PROSPECT, insulin-dependent diabetes and prior PCI were independent predictors of MACE related to non-culprit lesions, as well as plaque burden, thin-cap fibroatheroma, and a small minimal lumen area, which were not examined in our study ${ }^{17}$. Our results are consistent with the PROSPECT findings with respect to the impact of diabetes and prior PCI on any revascularisation. The TAXUS pooled programme also looked at predictors of TLR and non-TL TVR in years two to five. Predictors of TLR were (similar to this analysis) younger age, and pre-procedure vessel diameter and (different from this analysis) lesion length ${ }^{24}$. Predictors of non-TL TVR were diabetes (similar to this analysis), and hypertension treatment (different from this analysis) ${ }^{24}$. We identified several additional predictors of disease progression beyond the target lesion, such as hyperlipidaemia, target lesion location, diameter stenosis, and a trend for coronary calcification at baseline. In addition to baseline metabolic conditions, angiographic complexity plays a role in the progression of coronary artery disease. Coronary calcification has recently been identified as a strong indicator of adverse outcomes of PCI patients both in acute coronary syndromes and in the elective setting ${ }^{25,26}$. Interestingly, in our cohort, calcification in the target lesion had a stronger impact on non-TLR than on TLR. Another finding is the importance of the target lesion location. Interventions outside the LAD bear a higher risk of non-TLR. In other words, an untreated LAD is more often prone to reinterventions than the left circumflex and the right coronary artery combined. Two possible hypothetical explanations could be that LAD lesions progress more rapidly than non-LAD lesions, or that LAD lesions are more commonly underestimated and left untreated during the index procedure. Moreover, the LAD has such a large territory to supply that any progression has a clinical impact. The latter assumptions are underscored by fractional flow reserve studies ${ }^{27}$.

Additionally, a previous analysis by Taniwaki et al on predictors of TLR and predictors of all revascularisation was conducted from the RESOLUTE All Comers study ${ }^{15}$. Similar to our study, predictors of TLR were age, insulin-treated diabetes, in-stent restenosis, and $\mathrm{CABG}^{15}$. Our analysis probably benefited from the larger sample size of 6,137 patients and the clear differentiation between TLR and non-TLR.

\section{Limitations}

The present analysis has several limitations. It was a post hoc analysis of trials not primarily intended to investigate coronary artery disease progression, and almost $40 \%$ of patients came from RESOLUTE International, which used visual estimation of baseline angiographic characteristics and was not $100 \%$ monitored. However, both TLR and any revascularisation were pre-specified secondary endpoints of the trial, and events were adjudicated by a clinical events committee which used definitions harmonised across the RESOLUTE Global Clinical Program. Furthermore, compliance to cardiovascular medication, apart from dual antiplatelet therapy, was not available and therefore it was not possible to evaluate the impact of compliance on restenosis and progression of coronary artery disease. In addition, if a patient had a TLR and a non-TLR, that patient was excluded from the study to sharpen differences between both groups of patients. This analytic approach underestimates the actual rate of TLR and non-TLR. Finally, we do not know whether the clinical indication for repeat revascularisation differed between TLR and non-TLR, as these data are not available.

\section{Conclusions}

The RESOLUTE Global Clinical Program was associated with a low TLR rate at three years. Given this low rate of TLR, the cumulative incidence of non-TLR in patients treated with secondgeneration DES was almost three times higher than TLR. Predictors of non-TLR were often different from predictors of TLR. Further improvements in PCI outcomes will largely depend on prospectively identifying ischaemia-producing lesions and intensifying preventive therapies. 


\section{Impact on daily practice}

With contemporary drug-eluting stents, target lesion-related events after percutaneous coronary intervention (PCI) are markedly suppressed. The highly effective DES-based local therapy of coronary lesions is currently applied to a wide spectrum of patients, including those with more advanced coronary artery disease and complex anatomies. Consequently, revascularisation events that are not stent-related are prominent in the followup of contemporary PCI populations, and are three times higher than target lesion-related events. Therefore, further improvements in PCI outcomes will largely depend on prospectively identifying ischaemia-producing lesions and intensifying preventive therapies.

\section{Guest Editor}

This paper was guest edited by Rafael Beyar, MD, DSc, MPH; Director, Rambam Health Care Campus, Women's Division/ Dr Phillip and Sara Gotlieb Chair, Department of Medicine and Biomedical Engineering, Technion, Israel.

\section{Acknowledgements}

We thank Colleen Gilbert, PharmD, CMPP, Tim Peoples, MA, ELS, and Nicole Brilakis, MS, MBA, for editorial assistance, and Minglei Liu, PhD, and Yun Peng, MS, for statistical analysis and oversight (all from Medtronic).

\section{Funding}

This analysis and the studies contributing to it were sponsored by Medtronic, Inc.

\section{Conflict of interest statement}

M. Abdel-Wahab has received an institutional research grant from Medtronic and speaker honoraria from Boston Scientific. S. Silber has received grants from Medtronic. L. Mauri receives grants from Medtronic, Abbott Vascular, Boston Scientific, Eli Lilly/Daiichi Sankyo, Bristol Myers Squibb/Sanofi-Aventis, and Biotronik. A. Yeung has served as an advisor to Medtronic. J. Belardi is a consultant for Medtronic and for Eli Lilly. P. Widimský receives speaker honoraria from Medtronic. I. Meredith serves as a consultant to Boston Scientific and Medtronic. S. Saito is a speaker for Medtronic. Abbott Vascular, and Boston Scientific. G. Richardt has received an institutional research grant from Medtronic, and receives honoraria from Abbott Vascular for lectures and advisory board activities. The other authors have no conflicts of interest to declare. The Guest Editor has no conflicts of interest to declare.

\section{References}

1. Stefanini GG, Holmes DR Jr. Drug-eluting coronary-artery stents. N Engl J Med. 2013;368:254-65.

2. Kastrati A, Mehilli J, Pache J, Kaiser C, Valgimigli M, Kelbaek H, Menichelli M, Sabate M, Suttorp MJ, Baumgart D, Seyfarth M, Pfisterer ME, Schömig A. Analysis of 14 trials comparing sirolimus-eluting stents with bare-metal stents. $N$ Engl $J$ Med. 2007;356:1030-9.

3. Silber S, Windecker S, Vranckx P, Serruys PW; RESOLUTE All Comers investigators. Unrestricted randomised use of two new generation drug-eluting coronary stents: 2-year patient-related versus stent-related outcomes from the RESOLUTE All Comers trial. Lancet. 2011;377:1241-7.

4. Stone GW, Teirstein PS, Meredith IT, Farah B, Dubois CL, Feldman RL, Dens J, Hagiwara N, Allocco DJ, Dawkins KD; PLATINUM Trial Investigators. A prospective, randomized evaluation of a novel everolimus-eluting coronary stent: the PLATINUM (a Prospective, Randomized, Multicenter Trial to Assess an Everolimus-Eluting Coronary Stent System [PROMUS Element] for the Treatment of Up to Two de Novo Coronary Artery Lesions) trial. J Am Coll Cardiol. 2011;57:1700-8.

5. von Birgelen C, Sen H, Lam MK, Danse PW, Jessurun GA, Hautvast RW, van Houwelingen GK, Schramm AR, Gin RM, Louwerenburg JW, de Man FH, Stoel MG, Lowik MM, Linssen GC, Said SA, Nienhuis MB, Verhorst PM, Basalus MW, Doggen CJ, Tandjung K. Third-generation zotarolimus-eluting and everolimus-eluting stents in all-comer patients requiring a percutaneous coronary intervention (DUTCH PEERS): a randomised, single-blind, multicentre, non-inferiority trial. Lancet. 2014;383:413-23.

6. Dangas GD, Serruys PW, Kereiakes DJ, Hermiller J, Rizvi A, Newman W, Sudhir K, Smith RS Jr, Cao S, Theodoropoulos K, Cutlip DE, Lansky AJ, Stone GW. Meta-analysis of everolimuseluting versus paclitaxel-eluting stents in coronary artery disease: final 3-year results of the SPIRIT clinical trials program (Clinical Evaluation of the Xience V Everolimus Eluting Coronary Stent System in the Treatment of Patients With De Novo Native Coronary Artery Lesions). JACC Cardiovasc Interv. 2013;6:914-22.

7. Kedhi E, Joesoef KS, McFadden E, Wassing J, van Mieghem C, Goedhart D, Smits PC. Second-generation everolimus-eluting and paclitaxel-eluting stents in real-life practice (COMPARE): a randomised trial. Lancet. 2010;375:201-9.

8. Serruys PW, Silber S, Garg S, van Geuns RJ, Richardt G, Buszman PE, Kelbaek H, van Boven AJ, Hofma SH, Linke A, Klauss V, Wijns W, Macaya C, Garot P, DiMario C, Manoharan G, Kornowski R, Ischinger T, Bartorelli A, Ronden J, Bressers M, Gobbens P, Negoita M, van Leeuwen F, Windecker S. Comparison of zotarolimus-eluting and everolimus-eluting coronary stents. N Engl J Med. 2010;363:136-46.

9. Belardi JA, Widimsky P, Neumann FJ, Mauri L, Albertal M; RESOLUTE International Investigators. Real-world safety and effectiveness outcomes of a zotarolimus-eluting stent: final 3-year report of the RESOLUTE International study. J Interv Cardiol. 2013;26:515-23.

10. Mauri L, Leon MB, Yeung AC, Negoita M, Keyes MJ, Massaro JM. Rationale and design of the clinical evaluation of the Resolute zotarolimus-eluting coronary stent system in the treatment of de novo lesions in native coronary arteries (the RESOLUTE US clinical trial). Am Heart J. 2011;161:807-14. 
11. Meredith IT, Worthley S, Whitbourn R, Walters DL, McClean D, Horrigan M, Popma JJ, Cutlip DE, DePaoli A, Negoita M, Fitzgerald PJ; RESOLUTE Investigators. Clinical and angiographic results with the next-generation resolute stent system: a prospective, multicenter, first-in-human trial. JACC Cardiovasc Interv. 2009;2:977-85.

12. Meredith IT, Worthley SG, Whitbourn R, Walters D, McClean D, Ormiston J, Horrigan M, Wilkins GT, Hendriks R, Matsis P, Muller D, Cutlip DE. Long-term clinical outcomes with the next-generation Resolute Stent System: a report of the two-year follow-up from the RESOLUTE clinical trial. EuroIntervention. 2010;5:692-7.

13. Neumann FJ, Widimsky P, Belardi JA. One-year outcomes of patients with the zotarolimus-eluting coronary stent: RESOLUTE International Registry. EuroIntervention. 2012;7:1181-8.

14. Saito S, Prpic R, Popma JJ, Alexander J, Krucoff MW; ENDEAVOR Japan Investigators. The clinical evaluation of the Endeavor zotarolimus-eluting coronary stent in Japanese patients with de novo native coronary artery lesions: primary results and 3-year follow-up of the Endeavor Japan study. Cardiovasc Revasc Med. 2011;12:273-9.

15. Taniwaki M, Stefanini GG, Silber S, Richardt G, Vranckx P, Serruys PW, Buszman PE, Kelbaek H, Windecker S; RESOLUTE All-Comers Investigators. 4-year clinical outcomes and predictors of repeat revascularization in patients treated with new generation drug-eluting stents: a report from the RESOLUTE All Comers trial (A Randomized Comparison of a Zotarolimus-Eluting Stent With an Everolimus-Eluting Stent for Percutaneous Coronary Intervention). J Am Coll Cardiol. 2014;63:1617-25.

16. Yeung AC, Leon MB, Jain A, Tolleson TR, Spriggs DJ, Mc Laurin BT, Popma JJ, Fitzgerald PJ, Cutlip DE, Massaro JM, Mauri L; RESOLUTE US Investigators. Clinical evaluation of the Resolute zotarolimus-eluting coronary stent system in the treatment of de novo lesions in native coronary arteries: the RESOLUTE US clinical trial. J Am Coll Cardiol. 2011;57:1778-83.

17. Stone GW, Maehara A, Lansky AJ, de Bruyne B, Cristea E, Mintz GS, Mehran R, McPherson J, Farhat N, Marso SP, Parise H, Templin B, White R, Zhang Z, Serruys PW; PROSPECT Investigators. A prospective natural-history study of coronary atherosclerosis. N Engl J Med. 2011;364:226-35.

18. Stolker JM, Cohen DJ, Kennedy KF, Pencina MJ, Lindsey JB, Mauri L, Cutlip DE, Kleiman NS; Evaluation of Drug-Eluting Stents and Ischemic Events (EVENT) Investigators. Repeat revascularization after contemporary percutaneous coronary intervention: an evaluation of staged, target lesion, and other unplanned revascularization procedures during the first year. Circ Cardiovasc Interv. 2012;5:772-82.

19. Chacko R, Mulhearn M, Novack V, Novack L, Mauri L, Cohen SA, Moses J, Leon MB, Cutlip DE. Impact of target lesion and nontarget lesion cardiac events on 5-year clinical outcomes after sirolimus-eluting or bare-metal stenting. JACC Cardiovasc Interv. 2009;2:498-503.
20. Stone GW, Moses JW, Ellis SG, Schofer J, Dawkins KD, Morice MC, Colombo A, Schampaert E, Grube E, Kirtane AJ, Cutlip DE, Fahy M, Pocock SJ, Mehran R, Leon MB. Safety and efficacy of sirolimus- and paclitaxel-eluting coronary stents. $N$ Engl J Med. 2007;356:998-1008.

21. Kandzari DE, Leon MB, Meredith I, Fajadet J, Wijns W, Mauri L. Final 5-year outcomes from the Endeavor zotarolimuseluting stent clinical trial program: comparison of safety and efficacy with first-generation drug-eluting and bare-metal stents. JACC Cardiovasc Interv. 2013;6:504-12.

22. Caixeta A, Lansky AJ, Serruys PW, Hermiller JB, Ruygrok P, Onuma Y, Gordon P, Yaqub M, Miquel-Hebert K, Veldhof S, Sood P, Su X, Jonnavithula L, Sudhir K, Stone GW; Spirit II and III Investigators. Clinical follow-up 3 years after everolimus- and paclitaxel-eluting stents: a pooled analysis from the SPIRIT II (A Clinical Evaluation of the XIENCE V Everolimus Eluting Coronary Stent System in the Treatment of Patients With De Novo Native Coronary Artery Lesions) and SPIRIT III (A Clinical Evaluation of the Investigational Device XIENCE V Everolimus Eluting Coronary Stent System [EECSS] in the Treatment of Subjects With De Novo Native Coronary Artery Lesions) randomized trials. JACC Cardiovasc Interv. 2010;3:1220-8.

23. Silber S, Serruys PW, Leon MB, Meredith IT, Windecker S, Neumann FJ, Belardi J, Widimsky P, Massaro J, Novack V, Yeung AC, Saito S, Mauri L. Clinical outcome of patients with and without diabetes mellitus after percutaneous coronary intervention with the resolute zotarolimus-eluting stent: 2-year results from the prospectively pooled analysis of the international global RESOLUTE program. JACC Cardiovasc Interv. 2013;6:357-68.

24. Leon MB, Allocco DJ, Dawkins KD, Baim DS. Late clinical events after drug-eluting stents: the interplay between stent-related and natural history-driven events. JACC Cardiovasc Interv. 2009;2:504-12.

25. Kuramitsu S, Iwabuchi M, Haraguchi T, Domei T, Nagae A, Hyodo M, Yamaji K, Soga Y, Arita T, Shirai S, Kondo K, Ando K, Sakai K, Goya M, Takabatake Y, Sonoda S, Yokoi H, Toyota F, Nosaka H, Nobuyoshi M. Incidence and clinical impact of stent fracture after everolimus-eluting stent implantation. Circ Cardiovasc Interv. 2012;5:663-71.

26. Onuma Y, Tanimoto S, Ruygrok P, Neuzner J, Piek JJ, Seth A, Schofer JJ, Richardt G, Wiemer M, Carrie D, Thuesen L, Dorange C, Miquel-Hebert K, Veldhof S, Serruys PW. Efficacy of everolimus eluting stent implantation in patients with calcified coronary culprit lesions: two-year angiographic and three-year clinical results from the SPIRIT II study. Catheter Cardiovasc Interv. 2010;76:634-42.

27. Toth G, Hamilos M, Pyxaras S, Mangiacapra F, Nelis O, De Vroey F, Di Serafino L, Muller O, Van Mieghem C, Wyffels E, Heyndrickx GR, Bartunek J, Vanderheyden M, Barbato E, Wijns W, De Bruyne B. Evolving concepts of angiogram: fractional flow reserve discordances in 4000 coronary stenoses. Eur Heart J. 2014;35:2831-8. 